\title{
Associations of neighborhood social environment attributes and physical activity among 9-11 year old children from 12 countries
}

\section{Sullivan, Samaah M.}

2017-07

Sullivan , S M , Broyles , S T, Barreira , T V , Chaput , J-P , Fogelholm , M , Hu , G , Kuriyan , R , Kurpad, A , Lambert, E V , Maher , C Maia , J, Matsudo , V , Olds , T, Onywera , V , Sarmiento , O L , Standage , M , Tremblay, M S , Tudor-Locke , C , Zhao , P , Katzmarzyk , P T \& ISCOLE Res Grp 2017 , ' Associations of neighborhood social environment attributes and physical activity among 9-11 year old children from 12 countries ', Health \& Place, vol. 46 , pp. 183-191 . https://doi.org/10.1016/j.healthplace.2017.05.013

http://hdl.handle.net/10138/299406

https://doi.org/10.1016/j.healthplace.2017.05.013

publishedVersion

Downloaded from Helda, University of Helsinki institutional repository.

This is an electronic reprint of the original article.

This reprint may differ from the original in pagination and typographic detail.

Please cite the original version. 


\section{Associations of neighborhood social environment attributes and physical activity among 9-11 year old children from 12 countries}

Samaah M. Sullivan ${ }^{\mathrm{a}, \mathrm{b}, \mathrm{c}}$, Stephanie T. Broyles ${ }^{\mathrm{b}}$, Tiago V. Barreira ${ }^{\mathrm{b}, \mathrm{d}}$, Jean-Philippe Chaput ${ }^{\mathrm{e}}$, Mikael Fogelholm ${ }^{\mathrm{f}}$, Gang $\mathrm{Hu}^{\mathrm{b}}$, Rebecca Kuriyan ${ }^{\mathrm{g}}$, Anura Kurpad ${ }^{\mathrm{g}}$, Estelle V. Lambert ${ }^{\mathrm{h}}$, Carol Maher ${ }^{i}$, Jose Maia ${ }^{j}$, Victor Matsudo ${ }^{k}$, Tim Olds ${ }^{i}$, Vincent Onywera ${ }^{1}$, Olga L. Sarmiento ${ }^{\mathrm{m}}$, Martyn Standage $^{\mathrm{n}}$, Mark S. Tremblay ${ }^{\mathrm{e}}$, Catrine Tudor-Locke ${ }^{\mathrm{b}, \mathrm{o}}$, Pei Zhao ${ }^{\mathrm{p}}$, Peter

T. Katzmarzyk ${ }^{\mathrm{b}, *}$, for the ISCOLE Research Group

a Department of Epidemiology, Rollins School of Public Health, Emory University, Atlanta, GA, United States

b Pennington Biomedical Research Center, 6400 Perkins Road, Baton Rouge, LA 70808-4124, United States

${ }^{c}$ College of Humanities \& Social Sciences, Louisiana State University, Baton Rouge, LA, United States

a Department of Exercise Science, Syracuse University, Syracuse, NY, United States

e Children's Hospital of Eastern Ontario Research Institute, Ottawa, Canada

${ }^{\mathrm{f}}$ Department of Food and Environmental Sciences, University of Helsinki, Helsinki, Finland

${ }^{\mathrm{g}}$ St. Johns Research Institute, Bangalore, India

${ }^{\text {h }}$ Division of Exercise Science and Sports Medicine, Department of Human Biology, Faculty of Health Sciences, University of Cape Town, Cape Town, South Africa

${ }^{\mathrm{i}}$ Alliance for Research in Exercise Nutrition and Activity (ARENA), School of Health Sciences, University of South Australia, Adelaide, Australia

${ }^{\mathrm{j}}$ CIFI2D, Faculdade de Desporto, University of Porto, Porto, Portugal

k Centro de Estudos do Laboratório de Aptidão Física de São Caetano do Sul, Sao Paulo, Brazil

${ }^{1}$ Department of Recreation Management and Exercise Science, Kenyatta University, Nairobi, Kenya

${ }^{\mathrm{m}}$ School of Medicine, Universidad de los Andes, Bogota, Colombia

${ }^{n}$ Department for Health, University of Bath, Bath, United Kingdom

o Department of Kinesiology, University of Massachusetts Amherst, Amherst, United States

p Tianjin Women's and Children's Health Center, Tianjin, China

\section{A R T I C L E I N F O}

\section{Keywords:}

Social environment

Neighborhood environment

Physical activity

International

\begin{abstract}
A B S T R A C T
We investigated whether associations of neighborhood social environment attributes and physical activity differed among 12 countries and levels of economic development using World Bank classification (low/lowermiddle-, upper-middle- and high- income countries) among 9-11 year old children (N=6161) from the International Study of Childhood Obesity, Lifestyle, and the Environment (ISCOLE). Collective efficacy and perceived crime were obtained via parental/guardian report. Moderate-to-vigorous physical activity (MVPA) was assessed with waist-worn Actigraph accelerometers. Neighborhood environment by country interactions were tested using multi-level statistical models, adjusted for covariates. Effect estimates were reported by country and pooled estimates calculated across World Bank classifications for economic development using meta-analyses and forest plots. Associations between social environment attributes and MVPA varied among countries and levels of economic development. Associations were more consistent and in the hypothesized directions among countries with higher levels economic development, but less so among countries with lower levels of economic development.
\end{abstract}

\section{Introduction}

Physical inactivity is the fourth leading cause of death worldwide, and is recognized as a global pandemic (Kohl et al., 2012). For schoolaged children, global physical activity guidelines as well as those for the United States (US) call for a minimum of $60 \mathrm{~min}$ per day of moderate-

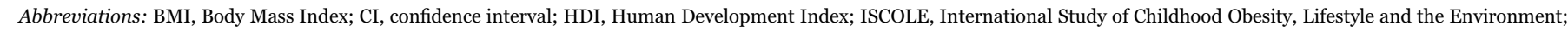
MVPA, moderate-to-vigorous physical activity; OR, odds ratio; SD, standard deviation; UK, United Kingdom; US, United States

* Corresponding author.

E-mail address: Peter.Katzmarzyk@pbrc.edu (P.T. Katzmarzyk). 


\begin{tabular}{|c|c|c|c|c|c|c|}
\hline & \multicolumn{6}{|l|}{ N (\%) } \\
\hline & HDI & $\mathrm{N}$ & Males & Females & $\begin{array}{l}\text { Highest Parental Education, } \\
\leq \text { High School) }\end{array}$ & $\begin{array}{l}\text { Age, y } \\
\text { (mean, SD) }\end{array}$ \\
\hline All Sites & - & 6161 & $2812(45.6)$ & $3349(54.4)$ & $2612(42.4)$ & $10.4(0.6)$ \\
\hline Low/Lower-Middle Income Countries & & 1033 & $473(45.8)$ & $560(54.2)$ & $271(26.2)$ & $10.5(0.5)$ \\
\hline Kenya (Nairobi) & 0.509 & 491 & $226(46.0)$ & $265(54.1)$ & $179(36.5)$ & $10.2(0.7)$ \\
\hline India (Bangalore) & 0.547 & 542 & $247(45.6)$ & $295(54.4)$ & $92(17.0)$ & $10.4(0.5)$ \\
\hline Upper-Middle Income Countries & & 2168 & $1047(48.3)$ & $1121(51.7)$ & $1345(62.0)$ & $10.3(0.6)$ \\
\hline South Africa (Cape Town) & 0.619 & 371 & $148(39.9)$ & $223(60.1)$ & $268(72.2)$ & $10.2(0.7)$ \\
\hline China (Tianjin) & 0.687 & 497 & $260(52.3)$ & $237(47.7)$ & $251(50.1)$ & $9.9(0.5)$ \\
\hline Colombia (Bogota) & 0.710 & 856 & $422(49.3)$ & $434(50.7)$ & $565(66.0)$ & $10.5(0.6)$ \\
\hline Brazil (São Paulo) & 0.718 & 444 & 217 (48.9) & $227(51.1)$ & $261(58.8)$ & $10.5(0.5)$ \\
\hline High Income Countries & & 2960 & $1292(43.7)$ & $1668(56.4)$ & $996(33.7)$ & $10.3(0.6)$ \\
\hline Portugal (Porto) & 0.809 & 603 & $261(43.3)$ & $342(56.7)$ & $476(78.9)$ & $10.4(0.3)$ \\
\hline UK (Bath \& North East Somerset) & 0.863 & 427 & $185(43.3)$ & $242(56.7)$ & $122(28.6)$ & $10.9(0.5)$ \\
\hline Finland (Helsinki, Espoo \& Vantaa) & 0.882 & 462 & $216(46.8)$ & $246(53.3)$ & $125(27.1)$ & $10.5(0.4)$ \\
\hline Canada (Ottawa) & 0.908 & 514 & $213(41.4)$ & $301(58.6)$ & $46(9.0)$ & $10.5(0.4)$ \\
\hline US (Baton Rouge) & 0.910 & 476 & $197(41.4)$ & $279(58.6)$ & $128(26.9)$ & $9.9(0.6)$ \\
\hline Australia (Adelaide) & 0.929 & 478 & $220(46.0)$ & $258(54.0)$ & $122(28.6)$ & $10.7(0.4)$ \\
\hline
\end{tabular}

Abbreviations: SD, standard deviation; HDI, human development index; ISCOLE, International Study of Childhood Obesity, Lifestyle and the Environment.

to-vigorous physical activity (MVPA) to achieve health benefits (World Health Organization, 2010). However, globally, $80 \%$ of adolescents do not achieve physical activity recommendations (Hallal et al., 2012). The lack of adequate levels of physical activity among children around the world is concerning, even in middle- and low- income countries where domestic and transport-related physical activities might contribute more to overall energy expenditure than leisure or recreational physical activities (Kohl et al., 2012; Hallal et al., 2012; Katzmarzyk and Mason, 2009; Dumith et al., 2011; Tremblay et al., 2016). Effective global promotion efforts for children's physical activity are dependent on understanding correlates and determinants across different socialcultural and environmental settings. With transitions in economic and social development, lifestyle behaviors such as physical activity also transition with increasing urbanization, availability of alternative modes of transportation, and increasing sedentary behaviors, referred to as the "Physical Activity Transition" (Katzmarzyk and Mason, 2009).

Theoretical frameworks such as ecological models have included environmental determinants of physical activity, which propose that physical activity is affected at multiple levels of influence including individual factors, the inter-personal/social environment, physical environment, and policy-level factors (Sallis et al., 2002a). Only a few studies have investigated associations between attributes of the neighborhood environment and physical activity (Ding et al., 2013; Sallis et al., 2009; Adams et al., 2013; Cerin et al., 2014) using multi-country samples; however, these studies focused on characteristics of the physical environment and were conducted only among adults. Further, these studies only included upper-middle and high-income countries (Adams et al., 2013; Cerin et al., 2014; Ding et al., 2013; Sallis et al., 2009). The existing research; however, does not provide a comprehensive examination of the association between aspects of the neighborhood social environment and children's physical activity globally or provide an examination of differences across multiple countries with varying levels of economic development.

Aspects of the social environment include dimensions such as interpersonal relationships (e.g., social support and social networks), social inequalities (e.g., socioeconomic position, income inequality, racial discrimination), and neighborhood characteristics (e.g., social cohesion and social capital). The neighborhood social environment may be an important setting to understand variations in children's physical activity levels. Single country studies, which have been mostly limited to North America, have shown that attributes of the neighborhood social environment such as crime and poor neighborhood safety are inversely associated with children's physical activity (Molnar et al.,
2004; Gomez et al., 2004; Janssen, 2014; Datar et al., 2013) while collective efficacy has been associated with higher levels of physical activity (Franzini et al., 2009; Kimbro et al., 2011). Collective efficacy, the willingness of people to intervene for the common good, is a form of social capital which measures individual perceptions of social cohesion and social control (Sampson et al., 1997). Neighborhoods with higher levels of collective efficacy are able to reinforce positive social norms such as physical activity and enforce ordinances and laws restricting negative behaviors (i.e., selling of illegal drugs or engaging in other illicit behaviors) increasing a sense of neighborhood safety which also promotes physical activity (Kawachi and Berkman, 2003; McNeill et al., 2006). Thus, through the collective neighborhood response of residents to do good deeds for others, intervene, and to achieve common goals for the neighborhood, collective efficacy is hypothesized to mediate public order and violence. Conversely, low levels of collective efficacy and perceived neighborhood safety may discourage and constrain physical activity behavior (Molnar et al., 2004; Burdette et al., 2006).

Given the lack of multi-country studies that focus on characteristics of the social environment among children, the main objective of this paper was to investigate whether associations of the neighborhood social environment (collective efficacy and perceived crime) and physical activity differed among 12 countries. A secondary objective of this study was to examine heterogeneity of associations among countries with different World Bank classifications of economic development divided into low/lower-middle-, upper-middle-, and highincome groups (World Bank, 2012) and ranked by the Human Development Index (HDI), which is a composite score based on life expectancy, gross national income, literacy and school participation (Table 1) (United Nations Development Programme, 2011).

We hypothesized that neighborhood-by-country interactions would be significant, indicating differences in the associations between neighborhood social environment attributes and physical activity. We expected variations among countries by World bank classification of economic development such that higher levels of collective efficacy would be associated with higher levels of physical activity while higher levels of perceived crime would be associated with lower levels of physical activity among children living in high- income countries. We did not expect to observe these associations among children living in countries with lower levels of economic development. In high- income countries with higher levels of development, physical activity has become largely optional (based on choice for leisure and recreational activities rather than need) (Sarmiento et al., 2015), and hence barriers such as perceived crime and facilitators such as collective efficacy 
would be likely associated in the hypothesized directions. In lowincome and middle- income countries; however, physical activity is largely obligatory for occupational, domestic, and transport-related physical activities despite crime perception and collective efficacy.

\section{Materials and methods}

\subsection{Study design and population}

The International Study of Childhood Obesity, Lifestyle and the Environment (ISCOLE) is a multi-national cross-sectional study that was designed to explore relationships between lifestyle behaviors and obesity among 9-11 year-old children from research sites in 12 countries: Australia (Adelaide), Brazil (Sao Paulo), Canada (Ottawa), Colombia (Bogota), Finland (Helsinki, Espoo, \& Vantaa), India (Bangalore), Kenya (Nairobi), Portugal (Porto), South Africa (Cape Town), United Kingdom (Bath \& NE Somerset), and the United States (Baton Rouge) (Katzmarzyk et al., 2013). Using World Bank classifications (World Bank, 2012), these countries were also divided into low/ lower-middle-, upper-middle-, and high- income groups and ranked by HDI. The Institutional Review Board at the Pennington Biomedical Research Center approved the overarching ISCOLE protocol, and the Institutional/Ethical Review Boards at each participating institution also approved the local protocol. Written informed consent was obtained from parents or legal guardians. If required by the local Institutional/Ethical Review Boards, child assent was also obtained.

A multi-stage sampling frame was used within each site to select children for recruitment. The primary sampling frame was schools, which were typically stratified by an indicator of socioeconomic status, and the secondary sampling frame was classrooms within the selected schools. The sampling strategy yielded a sex-balanced stratified sample of at least 500 children within each site with a mean age of approximately 10.4 years. The sampling frame included students from both urban and suburban areas. In brief, a total of 7372 children aged 9-11 years from 256 schools across the 12 study sites participated in ISCOLE from September 2011 to December 2013. After removing observations with missing values for parental education $(n=399)$, valid accelerometer values $(n=715)$, BMI $z$-score $(n=5)$, collective efficacy $(n=50)$ and crime safety $(n=42)$, the analytic sample included 6161 children. $P$-values for differences between included and excluded participants (Supplementary Table 1) were obtained using multi-level models with sites treated as fixed effects. Included participants were younger (10.39 vs. 10.44 years; $p<0.0001)$ and more likely to be female $(54.4 \%$ vs. $49.6 \% ; p=0.0003)$. Detailed information on the ISCOLE design and methods have been described elsewhere (Katzmarzyk et al., 2013).

\subsection{Measurements}

\subsubsection{Neighborhood social environment}

Characteristics of children's residential neighborhood environment were self-reported by their parents or guardians using a home and neighborhood environment questionnaire (Katzmarzyk et al., 2013). Following procedures by Sampson et al. (1997), collective efficacy was assessed as the average of two 5-item subscales: social cohesion and social control such that anyone responding to at least one item provided data for the analysis. Higher averaged scores indicated greater collective efficacy. In the ISCOLE analytic sample, the Cronbach alpha coefficients for collective efficacy, social cohesion, and social control were $0.81,0.74$, and 0.75 , respectively.

The measure of social cohesion included five items assessed on 5point Likert scales, ranging from strongly disagree (1) to strongly agree (5). Parents were asked how strongly they agreed that: 1) people around their neighborhood are willing to help their neighbors; 2) they had a close-knit neighborhood; 3) people in their neighborhood can be trusted; 4) people in their neighborhood generally don't get along with each other; and 5) people in their neighborhood do not share the same values, attitudes or beliefs. The last two items were reverse coded so that higher scores indicated higher social cohesion. Social control was assessed using five items which asked parents how much (using 5-point Likert scales ranging from very unlikely (1) to very likely (5)) their neighbors could be counted on to intervene in various ways if: 1) children were skipping school and hanging out on a street corner; 2) children were spray-painting graffiti on a local building; 3) a child was showing disrespect to an adult; 4) there was a fight in front of their house; and 5) the fire station closest to their home was threatened with budget cuts.

Perceived neighborhood crime safety was adapted from the Neighborhood Environment Walkability Scale for Youth (NEWS-Y) (Rosenberg et al., 2009). Parents were asked how strongly they agreed (using 4-point Likert scales ranging from strongly disagree (1) to strongly agree (4)), that: 1) there is a high crime rate; 2) they are afraid of their child being taken or hurt by a stranger on local streets; 3) they are afraid of their child being taken or hurt by a stranger in their yard, driveway, or common area; 4) they are afraid of their child being taken or hurt by a stranger in a local park; and 5) they are afraid of their child being taken or hurt by a known "bad" person (adult or child) in their neighborhood. A score for perceived neighborhood crime safety was assessed as the average of the responses across the 5 items (Cronbach $\alpha=0.86$ ) so that higher scores indicated higher crime.

\subsubsection{Physical activity}

Time spent in physical activity was objectively measured using ActiGraph GT3X+ accelerometers (ActiGraph LLC, Pensacola, FL, USA). Children were instructed to wear the accelerometers on a belt around their waist at the right mid-axillary line for $24 \mathrm{~h}$ per day for at least 7 consecutive days and to only remove the accelerometers during water-related activities. A valid accelerometer record required $\geq 4$ days with $\geq 10 \mathrm{~h}$ of waking wear time per day, including at least one weekend day. Data were collected at a sampling frequency of $80 \mathrm{~Hz}$ and downloaded using ActiLife software (version 5.64 or later, ActiGraph LLC). Raw accelerometer data were integrated into $1 \mathrm{~s}$ epochs and later aggregated to 60 and $15 \mathrm{~s}$ epochs with the low-frequency extension filter enabled. An automated algorithm was used to detect children's sleep-period and non-wear time (any sequence of at least 20 consecutive minutes of zero activity counts) (Barreira et al., 2015; TudorLocke et al., 2014). Once nocturnal sleep episode time and non-wear time were computed, waking wear time and the different activity levels and sedentary time were calculated and identified using the $15 \mathrm{~s}$ epoch data. Accelerometer thresholds for activity intensities were classified according to previously established cut-points by Evenson et al. (2008), where moderate-to-vigorous physical activity (MVPA) was defined as all activity $\geq 574$ counts per $15 \mathrm{~s}$, vigorous physical activity (VPA) was defined as activity $\geq 1003$ counts per $15 \mathrm{~s}$, and sedentary time (SED) was defined as all movement $\leq 25$ counts per $15 \mathrm{~s}$. Activity intensities were defined for before school, during school, after school, and weekend time periods using school-day schedules provided by each participating school. The full accelerometer protocol has been published elsewhere (Tudor-Locke et al., 2015).

\subsection{Covariates}

All models were adjusted for age, sex, and highest parental educational attainment as they were the only common demographic variables across all countries included in ISCOLE. Mean waking wear time was also included as a covariate in all models. Age was a continuous variable computed from the children's dates of birth. Parental educational attainment was based on the highest education level completed by either parent (completed less than or equal to a high school diploma or completed Bachelors/Postgraduate degree) as a measure of individual-level socioeconomic status (SES). Height and weight measures were used to calculate children's body mass index 
(BMI; $\mathrm{kg} / \mathrm{m}^{2}$ ). Using age- and sex- specific reference data from the World Health Organization (de Onis et al., 2007), BMI z-scores were computed and children were categorized as obese (BMI z-score $>+2$ $\mathrm{SD}$ ) or non-obese (BMI z-score $\leq+2 \mathrm{SD}$ ).

\subsection{Statistical analysis}

Descriptive statistics were calculated for the overall ISCOLE sample and by study site. Associations between neighborhood social environment variables and physical activity were calculated using multi-level mixed effects models (SAS PROC MIXED). Study sites were considered to have fixed effects, and schools nested within study sites were treated as random effects. Denominator degrees of freedom for statistical tests pertaining to fixed effects were calculated using the Kenward and Roger approximation (Kenward and Roger, 1997). A main-effect set of models estimated the associations between neighborhood social environment variables and physical activity controlling for confounders based on a priori theory (age, sex, and highest parental educational attainment, and mean waking wear time). In exploratory analysis, we further adjusted statistical models for obesity status; however, results were not different.

We further investigated a site-by-education interaction term to determine if individual-level SES modified the associations with physical activity measures among sites. The significance of interaction effects was evaluated by statistical significance and comparing model fit statistics. To examine whether the associations between each neighborhood social environment attribute (collective efficacy or perceived crime) and physical activity differed among countries, we evaluated the significance of neighborhood attribute-by-site interaction terms. Significant interactions $(p<0.05)$ suggested that the associations were different across countries (with the exception of MVPA before school), warranting country-specific estimates which were obtained using SAS PROC PLM and ESTIMATE options. Descriptive statistics, tests of interactions, and effect estimates across countries were calculated using SAS, version 9.4 (SAS Institute Inc., Cary, North Carolina).

Country-specific effect estimates were reported and then pooled estimates were calculated across World Bank classifications (low/ lower-middle-, upper-middle-, and high-income groups) using metaanalyses and forest plots in STATA, version 12.1 (StataCorp. College Station, Texas). The metan command was used to derive an inversevariance (I-V) weighted fixed-effect meta-analysis of country effects and pooled estimates were calculated for World Bank classification using subgroup analyses. Heterogeneity statistics relating to the extent that effect estimates varied among countries and levels of economic development are displayed in the forest plots, including the $I^{2}$ statistic, which describes the percentage of heterogeneity that is attributable to the variability in the treatment effect, rather than sampling variation. Using suggestions from Higgins et al. (2003), $I^{2}$ values were considered low for values between $25-50 \%$, moderate for $50-75 \%$, and high for $\geq 75 \%$. Due to significant heterogeneity of effect estimates across countries by economic development, it was inappropriate to metaanalyze across these groups (total pooled effect across all countries). However, we also performed a second meta-analysis of overall effects using a random effects model (DerSimonian and Laird (D-L)) which is also displayed in the forest plots.

\section{Results}

\subsection{Descriptive characteristics}

Table 1 shows descriptive characteristics for the ISCOLE sample, for each study site, and also pooled estimates for countries divided into low/lower-middle-, upper-middle,- and high-income groups and ranked by HDI. A total of $45.6 \%$ of the children were male and the mean age was 10.4 (SD: 0.6) years. Behavioral and neighborhood social environment characteristics of participants are shown in Table 2. Time spent in physical activities varied across study sites and contexts.

\subsection{Collective efficacy and MVPA}

Collective efficacy was positively associated with total MVPA among children in Finland ( $\beta=3.94 ; 95 \%$ CI: $1.04,6.84)$ and Australia ( $\beta=3.39$; $95 \%$ CI: $0.49,6.29)$; but was inversely associated with total MVPA among children in Kenya $(\beta=-2.58$; 95\% CI: $-5.00,-0.17)$ (Fig. 1A). Meta-analyses of country estimates showed that much of the heterogeneity was accounted for by level of economic development. Collective efficacy was inversely associated with MVPA among children in low/lower-middle- income countries $(\beta=-1.96$; 95\% CI: -3.72 , -0.19 ) while collective efficacy was positively associated with total MVPA among children in high-income countries $(\beta=1.86$; 95\% CI: $0.76,2.96)$.

The associations between collective efficacy and MVPA before school did not vary across countries (the collective efficacy-by-country interaction terms were not significant in regression analyses). These findings are also reflected in the meta-analyses and heterogeneity statistics between countries and subgroups (Fig. 1B). Thus, it was appropriate to pool estimates across countries which showed that collective efficacy was not significantly associated with MVPA before school (I-V Overall: $\beta=-0.03$; 95\% CI: $-0.20,0.13$ ).

Collective efficacy was significantly and positively associated with children's MVPA after school among children in Finland ( $\beta=3.17 ; 95 \%$ CI: $1.19,5.15)$, and Canada $(\beta=2.23 ; 95 \%$ CI: $0.28,4.18)$ and was marginally significant for children in the US ( $\beta=1.54$; $95 \%$ CI: -0.09 , 3.17) (Fig. 1C). There was significant heterogeneity of effect estimates across subgroups of economic development. Collective efficacy was only positively associated with MVPA after school ( $\beta=1.26$; $95 \%$ CI: $0.51,2.01$ ) among children pooled from high- income countries but was not significantly associated with MVPA after school among children pooled from low/lower-middle- income countries or uppermiddle- income countries.

Collective efficacy was significantly associated with weekend MVPA among children in the UK $(\beta=4.28 ; 95 \%$ CI: $0.11,8.45)$, Finland ( $\beta=4.31$; 95\% CI: $0.22,8.40$ ), and Australia $\beta=4.35$; 95\% CI: $0.26,8.44$ (Fig. 1D). However, collective efficacy was inversely associated with weekend MVPA among children in Kenya ( $\beta=-4.07$; 95\% CI: -7.49 , $-0.64)$. There was also significant heterogeneity of effect estimates across subgroups of economic development. Collective efficacy was only positively associated with weekend MVPA ( $\beta=2.60$; 95\% CI: 1.05 , 4.16) among children pooled from high- income countries.

\subsection{Perceived crime and MVPA}

Perceived crime was significantly associated with lower minutes of total MVPA among children in the UK $(\beta=-3.26$; 95\% CI: -6.33 , $-0.19)$ and Canada $(\beta=-2.74 ; 95 \%$ CI: $-5.29,-0.19)$; however, perceived crime was associated with higher minutes of total MVPA among children in Kenya ( $\beta=2.67$; 95\% CI: 0.35, 4.99) (Fig. 2A). Metaanalyses also showed that much of the heterogeneity was accounted for by differences across levels of economic development. Within the low/ lower-middle- income group, there was also significant within group heterogeneity $(\mathrm{p}=0.004)$. While the association between crime and total MVPA among children in Kenya was positive, the association was in the opposite direction for children in India. The pooled associations across economic subgroups showed that perceived crime was significantly associated with lower minutes of MVPA ( $\beta=-2.12$; 95\% CI: $-3.18,-1.06)$ among children in high- income countries but was not 
Table 2

Behavioral and Neighborhood Social Environment Characteristics of Participants by Study Site, ISCOLE (N=6161).

\begin{tabular}{|c|c|c|c|c|c|c|c|}
\hline & \multirow[b]{2}{*}{$\mathrm{N}$} & \multicolumn{4}{|c|}{ Mean Minutes/day of MVPA (SD) } & \multicolumn{2}{|l|}{ Mean (SD) } \\
\hline & & Total & Before School & After School & Weekend & Collective Efficacy ${ }^{\mathrm{a}}$ & Perceived Crime ${ }^{b}$ \\
\hline All Sites & 6161 & $60.2(24.8)$ & $6.4(6.2)$ & $29.8(17.6)$ & $55.4(31.9)$ & $3.5(0.7)$ & $2.6(0.9)$ \\
\hline Low/Lower-Middle Income Countries & 1033 & $59.5(28.8)$ & $7.1(7.5)$ & $24.9(13.6)$ & $59.7(37.0)$ & $3.4(0.7)$ & $2.6(0.8)$ \\
\hline Kenya (Nairobi) & 491 & $71.5(31.4)$ & $10.0(9.6)$ & $26.9(14.6)$ & $74.0(40.7)$ & $3.4(0.7)$ & $2.6(0.8)$ \\
\hline India (Bangalore) & 542 & $48.6(20.9)$ & $4.6(3.3)$ & $23.1(12.5)$ & $46.6(27.3)$ & $3.5(0.7)$ & $2.5(0.7)$ \\
\hline Upper-Middle Income Countries & 2168 & $60.2(25.0)$ & $7.0(7.1)$ & $32.0(20.7)$ & $55.9(32.0)$ & $3.4(0.7)$ & $3.1(0.8)$ \\
\hline South Africa (Cape Town) & 371 & $63.4(25.5)$ & $6.1(4.7)$ & $40.8(19.6)$ & $62.7(33.8)$ & $3.4(0.8)$ & $3.1(0.8)$ \\
\hline China (Tianjin) & 497 & $45.3(15.8)$ & $5.8(4.0)$ & $16.3(8.3)$ & $42.1(22.4)$ & $3.8(0.6)$ & $2.8(0.7)$ \\
\hline Colombia (Bogota) & 856 & $68.1(24.8)$ & $6.3(5.6)$ & $40.5(21.0)$ & $62.0(32.2)$ & $3.4(0.8)$ & $3.4(0.7)$ \\
\hline Brazil (São Paulo) & 444 & $59.1(25.8)$ & $10.5(11.4)$ & $26.0(18.2)$ & $54.0(33.9)$ & $3.2(0.6)$ & $2.9(0.6)$ \\
\hline High Income Countries & 2960 & $60.5(23.0)$ & $5.7(4.7)$ & $29.9(15.9)$ & $53.5(29.8)$ & $3.6(0.7)$ & $2.2(0.8)$ \\
\hline Portugal (Porto) & 603 & $56.0(21.9)$ & $5.6(5.6)$ & $25.1(13.2)$ & $44.7(26.8)$ & $3.5(0.7)$ & $2.6(0.7)$ \\
\hline UK (Bath \& North East Somerset) & 427 & $64.3(22.5)$ & $8.1(5.4)$ & $30.8(13.9)$ & $57.7(30.1)$ & $3.7(0.7)$ & $2.1(0.6)$ \\
\hline Finland (Helsinki, Espoo \& Vantaa) & 462 & $70.8(26.2)$ & $4.2(3.9)$ & $45.1(20.8)$ & $61.3(33.8)$ & $3.7(0.7)$ & $1.6(0.6)$ \\
\hline Canada (Ottawa) & 514 & $58.7(19.4)$ & $6.0(4.0)$ & $26.5(12.1)$ & $49.7(24.1)$ & $3.8(0.7)$ & $2.0(0.7)$ \\
\hline US (Baton Rouge) & 476 & $49.8(18.9)$ & $3.8(2.4)$ & $26.2(12.1)$ & $56.1(30.1)$ & $3.7(0.8)$ & $2.4(0.8)$ \\
\hline Australia (Adelaide) & 478 & $65.1(23.2)$ & $7.0(4.7)$ & $27.8(12.9)$ & $55.1(30.7)$ & $3.5(0.7)$ & $2.4(0.7)$ \\
\hline
\end{tabular}

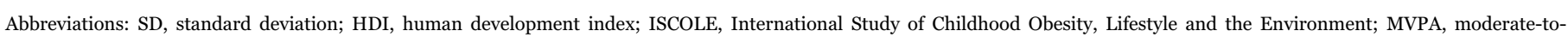
vigorous physical activity.

a 10 items assessed as 5-point Likert scales that measure as the wiliness of people to intervene for the common good and measures individual perceptions of social cohesion. Collective efficacy was the average of the responses provided so that anyone responding to at least one item provided data for the analysis. Higher scores indicate higher collective efficacy.

${ }^{\mathrm{b}} 5$ items assessed as 4-point Likert scales that measure parental perceptions of neighborhood safety and crime. A score was assessed as the average of the responses across the 5 items. Higher scores indicate higher perceived crime.
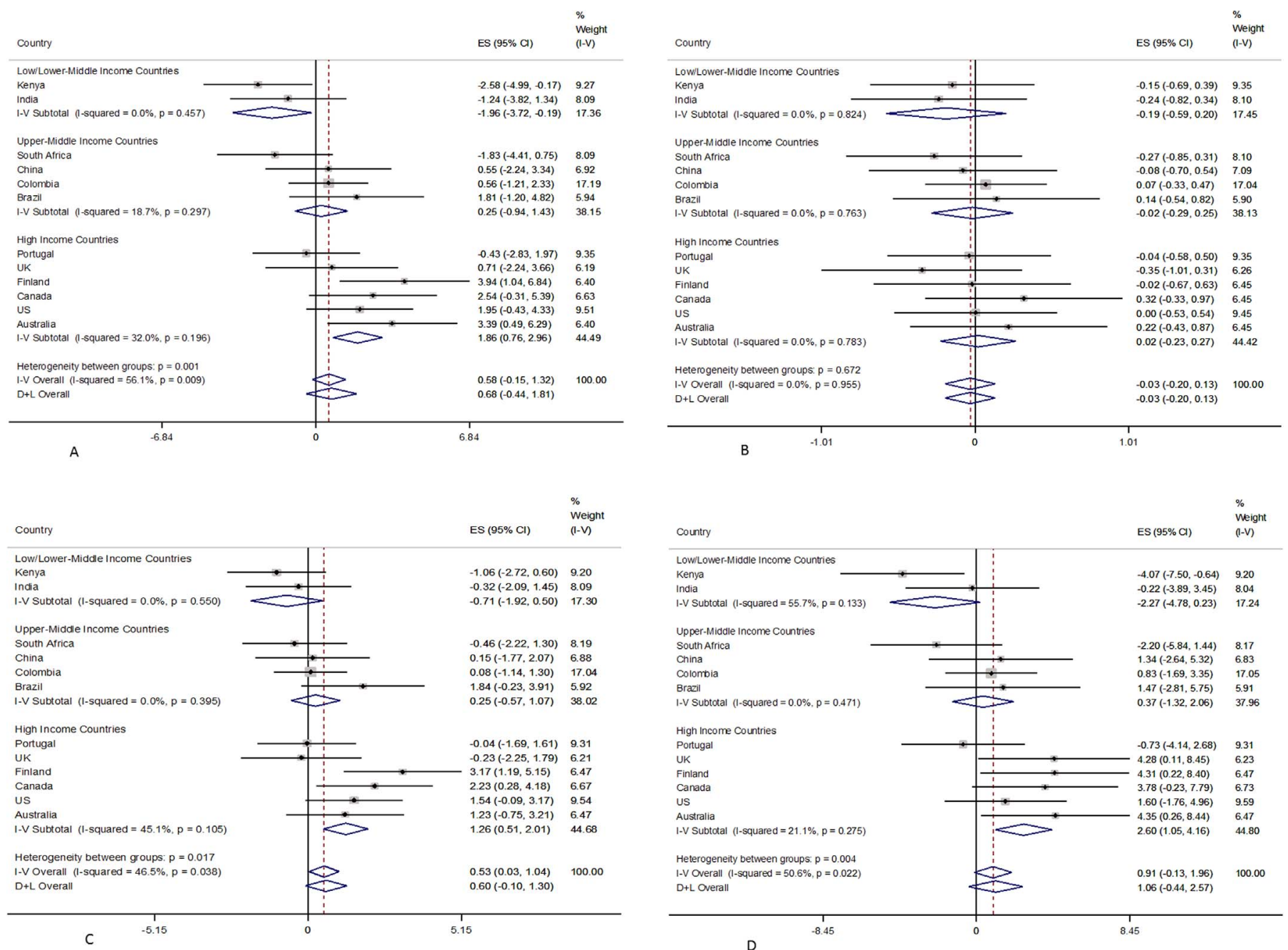

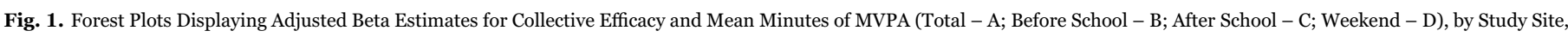

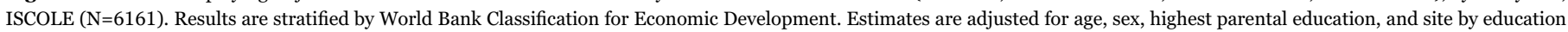
interaction. Error bars represent 95\% confidence intervals. 

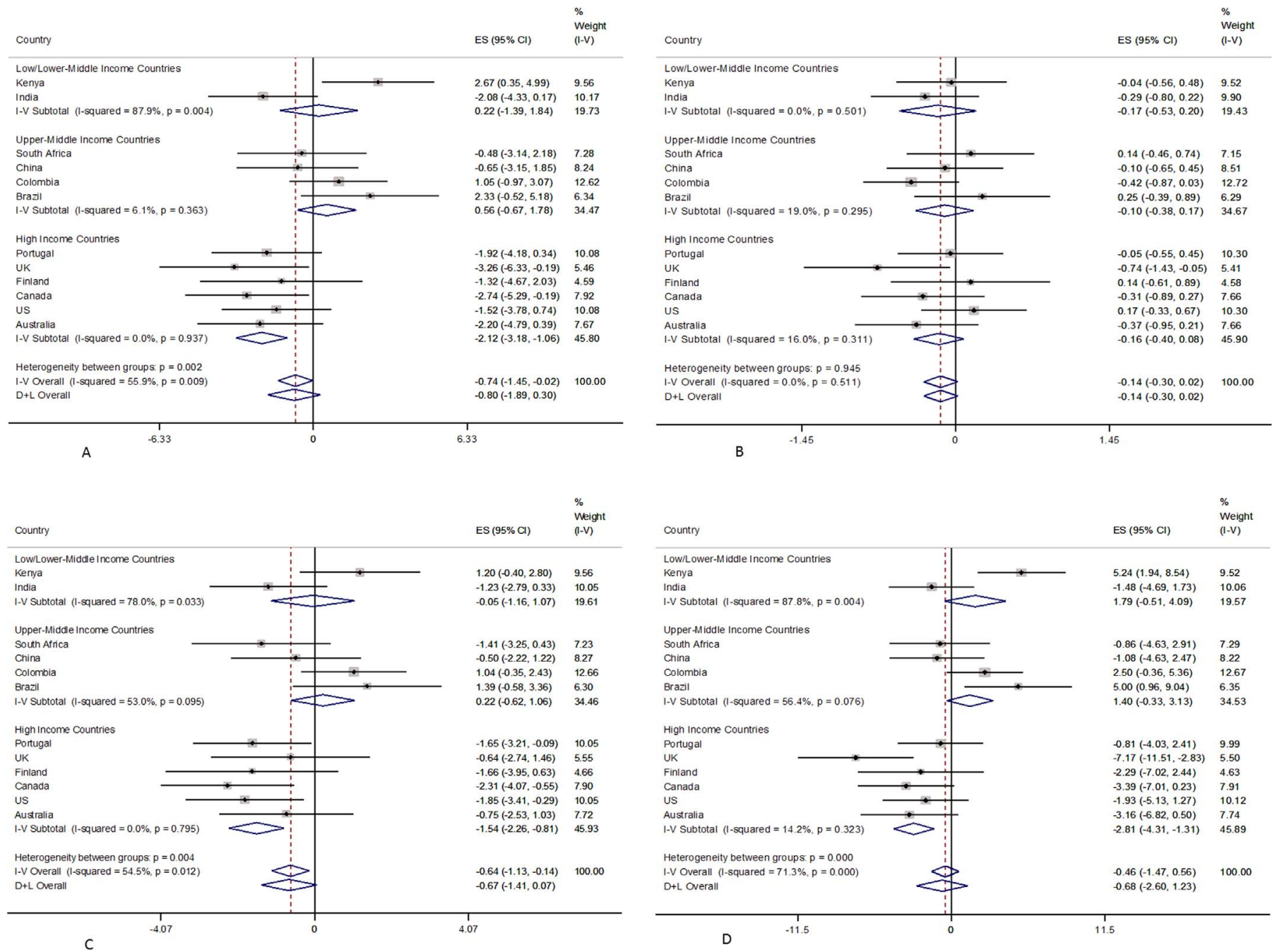

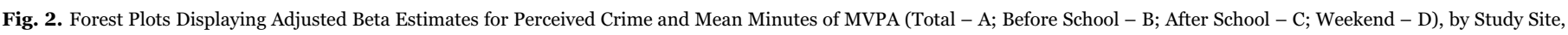

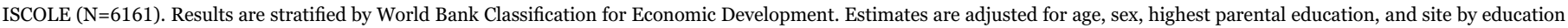
interaction. Error bars represent 95\% confidence intervals.

significantly associated with total MVPA among children from low/ lower-middle- income countries or upper-middle- income countries.

The associations between crime and MVPA before school did not vary across countries (the collective efficacy-by-country interaction was not significant in regression analyses). These findings are also reflected in the meta-analyses and heterogeneity statistics between countries and subgroups (Fig. 2B). Since there was no significant heterogeneity between countries or subgroups of economic development, it was appropriate to pool estimates across countries. Pooled overall, crime was not significantly associated with MVPA before school (I-V Overall: $\beta=-0.14$; 95\% CI: $-0.30,0.02$ ).

Perceived crime was significantly associated with lower MVPA after school among children in Portugal $(\beta=-1.65 ; 95 \%$ CI: $-3.21,-0.09)$, Canada ( $\beta=-2.31 ; 95 \%$ CI: $-4.07,-0.55)$, and the US $(\beta=-1.85 ; 95 \%$ CI: $-3.41,-0.29$ ) (Fig. 2C). Meta-analyses showed that much of the heterogeneity was accounted for by differences across levels of economic development. Within the low/lower-middle income group, there was also significant within-group heterogeneity $(\mathrm{p}=0.033)$. Again, while the association between crime and total MVPA among children in Kenya was positive, the association was in the opposite direction for children in India. Perceived crime was significantly associated with lower MVPA after school ( $\beta=-1.54$; 95\% CI: $-2.26,-0.81)$ among children pooled from high- income countries but was not significantly associated with MVPA after school among children pooled from low/ lower-middle- income countries or upper-middle- income countries.
Perceived crime was also associated with significantly lower weekend MVPA among children in the UK ( $\beta=-7.17 ; 95 \%$ CI: -11.51 , -2.83 ) and higher weekend MVPA among children in Kenya ( $\beta=5.24$; 95\% CI: 1.94, 8.54) and Brazil ( $\beta=5.00$; 95\% CI: 0.96, 9.04) (Fig. 2 D). Consistent with previous results, meta-analyses showed that much of the heterogeneity was accounted for by differences in economic development. Also, within the low/lower-middle income group, there was significant within-group heterogeneity $(p=0.004)$ between Kenya and India as their effect estimates are on opposite sides of the null value. Perceived crime was significantly associated with lower minutes of weekend MVPA among children pooled from high- income countries ( $\beta=-2.81$; 95\% CI: $-4.31,-1.31$ ), but was not significantly associated with weekend MVPA among children from low/lower-middle- income countries or upper-middle- income countries.

\section{Discussion}

The present study showed that the associations between neighborhood social environment variables and physical activity among children varied among countries and that there was significant heterogeneity of associations across levels of economic development. Associations of collective efficacy and MVPA (total, after school, and weekend) were more consistent and in the hypothesized direction among high- income countries and among countries with higher levels of HDI. Interestingly, in low/lower-middle- income countries, some associations were in the 
opposite direction as hypothesized, although only a few achieved statistical significance. Associations of perceived crime and MVPA (total after school, and weekend) were also more consistent and in the hypothesized directions among high- income countries and with higher levels of HDI. These associations were less consistent and some in the opposite of the hypothesized direction among children from lower- income countries.

Inconsistent results across countries with different levels of economic development may be explained by factors related to income and wealth (e.g., motor vehicles, physical activity for active transport, and sedentary behaviors). Countries with higher levels of economic development differ in social patterning of the behaviors related to physical activity shifting from high levels of occupational and transportationbased physical activity to more sedentary lifestyles, described as the "Physical Activity Transition"(Katzmarzyk and Mason, 2009). Also, in high- income countries, physical activity has become largely optional (based on choice rather than need) (Sarmiento et al., 2015), and hence barriers such as perceived crime and facilitators such as collective efficacy would be likely associated in the hypothesized directions. In countries with lower levels of economic development; however, physical activity is largely obligatory, and children may accumulate high levels of MVPA despite perception of high crime and/or low levels of collective efficacy.

Another point of discussion is related to the inconsistencies in associations across different context-specific domains of physical activity and aspects of the neighborhood social environment. Context-specific domains of physical activity do not distinguish between different types of activities (e.g., active school transport versus leisure activity). We would not expect to find significant associations between before-school MVPA and aspects of the social environment since before-school MVPA likely encompasses only active school transport that is obligatory (rather than leisure activity that is by choice) despite high crime perception and low collective efficacy. Similarly, MVPA after school likely encompasses active school transport as well as discretionary (leisure) physical activity contributing to differences in associations observed between countries with low- and high- levels of economic development.

Complicating the comparison of results in this study to those that do exist (although limited to North America and lacking comparisons to middle- and low- income countries) are the differences in neighborhood measures and differences in the assessment of physical activity. Kimbro et al. (2011) also found that higher maternal perceptions of neighborhood collective efficacy were associated with more hours of (weekday) outdoor play among young children in the US. However, outdoor play was not objectively measured and was totaled across the entire day. Franzini et al. (2009) also found that a favorable social environment was associated with several measures of physical activity among children. However, measures of collective efficacy, collective socialization of children, neighborhood exchange, social ties, and perceived safety were used as latent variables of the social environment. Furthermore, physical activity levels were not objectively measured, and did not include context-specific domains of physical activity (Franzini et al., 2009).

Molnar et al. (2004) found that lower parental report of neighborhood safety was significantly associated with lower physical activity among children living in the US. Physical activity; however, was measured as extracurricular activities (recreational) and was reported by the child's primary caregiver. Studies conducted by Gomez et al. (2004) (US) and Janssen (2014) (Canada), also found inverse associations between crime and physical activity. In both of these studies, after-school physical activity measures were self-reported. Other studies (Sallis et al., 1999, 2002b) did not find a significant association between perceived neighborhood safety and objective measures of physical activity, although measures of physical activity were not context-specific.

This study provided a unique opportunity to examine whether perceived attributes of the neighborhood social environment and children's physical activity differed across 12 countries representing a range of economic and human development. Further, data utilized from ISCOLE employed common standardized methods across countries and used objective measures of physical activity. Having common standardized methods across countries to allow for multi-country comparisons is a major advantage of this study, helping to examine whether associations are generalizable across countries and economies. Also, accelerometer data matched to local daily school start and end times enabled the present study to examine context-specific domains of physical activity.

\section{Limitations}

First, causality and temporality cannot be established due to the cross-sectional study design. Further, we cannot exclude the possibility of unmeasured confounding between developing and developed countries. We did not specifically examine confounding or mediating behaviors related to income and wealth (e.g., availability of motor vehicles, physical activity for active transport, nutrition, and sedentary behaviors) which may explain differences in associations observed among countries with different levels of economic development. The generalizability of these findings should be interpreted with caution. ISCOLE was not designed to be a nationally representative sample of children within each country; however, a recent publication by LeBlanc et al. (2015) which compared distributions of obesity, physical activity, and screen time within each ISCOLE country with national or regional surveys when available concluded that the samples were not systematically different. Also, while the questionnaires used to collect information on neighborhood characteristics were developed based on validated surveys, whether these are valid and have the same meaning in all countries may also be a limitation. To minimize this limitation, we examined the internal consistency of the measures overall and within each site. The Cronbach alpha coefficients were above 0.71 within all study sites, providing some evidence that these measures had good internal consistency and scale reliability within countries. Also, regional adaptions of some of the neighborhood assessment items were necessary, although limited. Since measures of the neighborhood environment were self-reported, misclassification and bias are also possible.

\section{Conclusions}

Aspects of the social environment may be potential targets to increase physical activity among children, especially in high- income countries with higher levels of human development. In lower income and less developed countries, these potential influences may be overridden by other priorities. Future research should continue to explore potential differences in behaviors (e.g., physical activity, transportation, sedentary behaviors) in regards to income and wealth and how these associations may differ across countries with varying levels of economic and human development. Further, it was beyond the scope of this paper to study the combined associations between aspects of the social environment or investigate associations with obesity; however, future research should explore these topics.

\section{Conflict of interest statement}

MF has received a research grant from Fazer Finland and has received an honorarium for speaking for Merck. AK has been a member of the Advisory Boards of Dupont and McCain Foods. RK has received a research grant from Abbott Nutrition Research and Development. VM is a member of the Scientific Advisory Board of Actigraph and has received an honorarium for speaking for The Coca-Cola Company. TO has received an honorarium for speaking for The Coca-Cola Company. The authors reported no other potential conflicts of interest. 


\section{Funding/Support}

ISCOLE was funded by The Coca-Cola Company. SMS reports postdoctoral funding through Emory University by the National Institutes of Health T32 grant THL130025A. The funders had no role in the design and conduct of the study; collection, management, analysis and interpretation of the data; and preparation, review or approval of the manuscript.

\section{Trial registration}

ClinicalTrials.gov: Identifier NCT01722500.

\section{Acknowledgements}

We wish to thank the ISCOLE External Advisory Board and the ISCOLE participants and their families who made this study possible. The ISCOLE Research Group includes: Coordinating Center, Pennington Biomedical Research Center: Peter T. Katzmarzyk, PhD (Co-PI), Timothy S. Church, MD, PhD (Co-PI), Denise G. Lambert, RN (Project Manager), Tiago Barreira, PhD, Stephanie Broyles, PhD, Ben Butitta, BS, Catherine Champagne, PhD, RD, Shannon Cocreham, MBA, Kara D. Denstel, MPH, Katy Drazba, MPH, Deirdre Harrington, $\mathrm{PhD}$, William Johnson, PhD, Dione Milauskas, MS, Emily Mire, MS, Allison Tohme, MPH, Ruben Rodarte MS, MBA; Data Management Center, Wake Forest University: Bobby Amoroso, BS, John Luopa, BS, Rebecca Neiberg, MS, Scott Rushing, BS; Australia, University of South Australia: Timothy Olds, PhD (Site Co-PI), Carol Maher, PhD (Site Co-PI), Lucy Lewis, PhD, Katia Ferrar, B Physio (Hon), Effie Georgiadis, BPsych, Rebecca Stanley, BAppSc (OT) Hon; Brazil, Centro de Estudos do Laboratório de Aptidão Física de São Caetano do Sul (CELAFISCS): Victor Keihan Rodrigues Matsudo, MD, PhD (Site PI), Sandra Matsudo, MD, PhD, Timoteo Araujo, MSc, Luis Carlos de Oliveira, MSc, Luis Fabiano, BSc, Diogo Bezerra, BSc, Gerson Ferrari, MSc; Canada, Children's Hospital of Eastern Ontario Research Institute: Mark S. Tremblay, PhD (Site Co-PI), Jean-Philippe Chaput, PhD (Site Co-PI), Priscilla Bélanger, MA, Mike Borghese, MSc, Charles Boyer, MA, Allana LeBlanc, MSc, Claire Francis, M.Sc.,Geneviève Leduc, PhD; China, Tianjin Women's and Children's Health Center: Pei Zhao, MD (Site Co-PI), Gang $\mathrm{Hu}, \mathrm{MD}, \mathrm{PhD}$ (Site Co-PI), Chengming Diao, MD, Wei Li, MD, Weiqin Li, MSc, Enqing Liu, MD, Gongshu Liu, MD, Hongyan Liu, MD, Jian Ma, MD, Yijuan Qiao, MD, Huiguang Tian, PhD, Yue Wang, MD, Tao Zhang, MSc, Fuxia Zhang, MD; Colombia, Universidad de los Andes: Olga Sarmiento, MD, PhD (Site PI), Julio Acosta, Yalta Alvira, BS, Maria Paula Diaz, Rocio Gamez, BS, Maria Paula Garcia, Luis Guillermo Gómez, Lisseth Gonzalez, Silvia Gonzalez, RD, Carlos Grijalba, MD, Leidys Gutierrez, David Leal, Nicolas Lemus, Etelvina Mahecha, BS, Maria Paula Mahecha, Rosalba Mahecha, BS, Andrea Ramirez, MD, Paola Rios, MD, Andres Suarez, Camilo Triana; Finland, University of Helsinki: Mikael Fogelholm, ScD (SitePI), Elli Hovi, BS, Jemina Kivelä, Sari Räsänen, BS, Sanna Roito, BS, Taru Saloheimo, MS, Leena Valta; India, St. Johns Research Institute: Anura Kurpad, MD, PhD (Site Co-PI), Rebecca Kuriyan, PhD (Site Co-PI), Deepa P. Lokesh, BSc, Michelle Stephanie D'Almeida, BSc, Annie Mattilda R, MSc, Lygia Correa, BSc, Vijay Dakshina Murthy, BSc; Kenya, Kenyatta University: Vincent Onywera, PhD (Site Co-PI), Mark S. Tremblay, PhD (Site Co-PI), Lucy-Joy Wachira, PhD, Stella Muthuri, PhD; Portugal, University of Porto: Jose Maia, PhD (Site PI), Alessandra da Silva Borges, BA, Sofia Oliveira Sá Cachada, Msc, Raquel Nichele de Chaves, MSc, Thayse Natacha Queiroz Ferreira Gomes, PhD, MSc, Sara Isabel Sampaio Pereira, BA, Daniel Monteiro de Vilhena e Santos, PhD, Fernanda Karina dos Santos, MSc, Pedro Gil Rodrigues da Silva, BA, Michele Caroline de Souza, MSc; South Africa, University of Cape Town: Vicki Lambert, PhD (Site PI), Matthew April, BSc (Hons), Monika Uys,
BSc (Hons), Nirmala Naidoo, MSc, Nandi Synyanya, Madelaine Carstens, BSc(Hons); United Kingdom, University of Bath: Martyn Standage, PhD (Site PI), Sean Cumming, PhD, Clemens Drenowatz, PhD, Lydia Emm, MSc, Fiona Gillison, PhD, Julia Zakrzewski, PhD; United States, Pennington Biomedical Research Center: Catrine Tudor-Locke, PhD (Site-PI), Ashley Braud, Sheletta Donatto, MS, LDN, RD, Corbin Lemon, BS, Ana Jackson, BA, Ashunti Pearson, MS, Gina Pennington, BS, LDN, RD, Daniel Ragus, BS, Ryan Roubion, John Schuna, Jr., PhD; Derek Wiltz. The ISCOLE External Advisory Board includes Alan Batterham, $\mathrm{PhD}$, Teesside University, Jacqueline Kerr, PhD, University of California, San Diego; Michael Pratt, MD, Centers for Disease Control and Prevention, Angelo Pietrobelli, MD, Verona University Medical School.

\section{Appendix A. Supporting information}

Supplementary data associated with this article can be found in the online version at doi:10.1016/j.healthplace.2017.05.013.

\section{References}

Adams, M.A., Ding, D., Sallis, J.F., Bowles, H.R., Ainsworth, B.E., Bergman, P., Bull, F.C., Carr, H., Craig, C.L., De Bourdeaudhuij, I., Gomez, L.F., Hagstromer, M., KlassonHeggebo, L., Inoue, S., Lefevre, J., Macfarlane, D.J., Matsudo, S., Matsudo, V., McLean, G., Murase, N., Sjostrom, M., Tomten, H., Volbekiene, V., Bauman, A., 2013. Patterns of neighborhood environment attributes related to physical activity across 11 countries: a latent class analysis. Int. J. Behav. Nutr. Phys. Act. 10, 34.

Barreira, T.V., Schuna, J.M., Jr., Mire, E.F., Katzmarzyk, P.T., Chaput, J.P., Leduc, G. Tudor-Locke, C., 2015. Identifying children's nocturnal sleep using 24-h waist accelerometry. Med. Sci. Sports Exerc. 47, 937-943.

Burdette, H.L., Wadden, T.A., Whitaker, R.C., 2006. Neighborhood safety, collective efficacy, and obesity in women with young children. Obes. (Silver Spring) 14 , $518-525$.

Cerin, E., Cain, K.L., Conway, T.L., Van Dyck, D., Hinckson, E., Schipperijn, J., De Bourdeaudhuij, I., Owen, N., Davey, R.C., Hino, A.A., Mitas, J., Orzanco-Garralda, R., Salvo, D., Sarmiento, O.L., Christiansen, L.B., Macfarlane, D.J., Schofield, G., Sallis, J.F., 2014. Neighborhood environments and objectively measured physical activity in 11 countries. Med. Sci. Sports Exerc. 46, 2253-2264.

Datar, A., Nicosia, N., Shier, V., 2013. Parent perceptions of neighborhood safety and children's physical activity, sedentary behavior, and obesity: evidence from a national longitudinal study. Am. J. Epidemiol. 177, 1065-1073.

Ding, D., Adams, M.A., Sallis, J.F., Norman, G.J., Hovell, M.F., Chambers, C.D., Hofstetter, C.R., Bowles, H.R., Hagstromer, M., Craig, C.L., Gomez, L.F., De Bourdeaudhuij, I., Macfarlane, D.J., Ainsworth, B.E., Bergman, P., Bull, F.C., Carr, H., Klasson-Heggebo, L., Inoue, S., Murase, N., Matsudo, S., Matsudo, V., McLean, G., Sjostrom, M., Tomten, H., Lefevre, J., Volbekiene, V., Bauman, A.E., 2013. Perceived neighborhood environment and physical activity in 11 countries: do associations differ by country? Int. J. Behav. Nutr. Phys. Act. 10, 57.

Dumith, S.C., Hallal, P.C., Reis, R.S., Kohl, H.W., 2011. Worldwide prevalence of physical inactivity and its association with human development index in 76 countries. Prev. Med. 53, 24-28.

Evenson, K.R., Catellier, D.J., Gill, K., Ondrak, K.S., McMurray, R.G., 2008. Calibration of two objective measures of physical activity for children. J. Sports Sci. 26, 1557-1565.

Franzini, L., Elliott, M.N., Cuccaro, P., Schuster, M., Gilliland, M.J., Grunbaum, J.A., Franklin, F., Tortolero, S.R., 2009. Influences of physical and social neighborhood environments on children's physical activity and obesity. Am. J. Public Health 99, $271-278$.

Gomez, J.E., Johnson, B.A., Selva, M., Sallis, J.F., 2004. Violent crime and outdoor physical activity among inner-city youth. Prev. Med. 39, 876-881.

Hallal, P.C., Andersen, L.B., Bull, F.C., Guthold, R., Haskell, W., Ekelund, U., Lancet Physical Activity Series Working Group. 2012. Global physical activity levels: surveillance progress, pitfalls, and prospectsLancet 380, 247-257.

Higgins, J.P., Thompson, S.G., Deeks, J.J., Altman, D.G., 2003. Measuring inconsistency in meta-analyses. BMJ 327, 557-560.

Janssen, I., 2014. Crime and perceptions of safety in the home neighborhood are independently associated with physical activity among 11-15 year olds. Prev. Med. 66, 113-117.

Katzmarzyk, P.T., Mason, C., 2009. The physical activity transition. J. Phys. Act. Health 6, 269-280.

Katzmarzyk, P.T., Barreira, T.V., Broyles, S.T., Champagne, C.M., Chaput, J.P., Fogelholm, M., Hu, G., Johnson, W.D., Kuriyan, R., Kurpad, A., Lambert, E.V., Maher, C., Maia, J., Matsudo, V., Olds, T., Onywera, V., Sarmiento, O.L., Standage, M., Tremblay, M.S., Tudor-Locke, C., Zhao, P., Church, T.S., 2013. The International Study of Childhood Obesity, Lifestyle and the Environment (ISCOLE): design and methods. BMC Public Health 13, 900.

Kawachi, I., Berkman, L., 2003. Neighborhoods and Health. Oxford University Press, New York. 
Kenward, M.G., Roger, J.H., 1997. Small sample inference for fixed effects from restricted maximum likelihood. Biometrics 53, 983-997.

Kimbro, R.T., Brooks-Gunn, J., McLanahan, S., 2011. Young children in urban areas: links among neighborhood characteristics, weight status, outdoor play, and television watching. Soc. Sci. Med. 72, 668-676.

Kohl, H.W., Craig, C.L., Lambert, E.V., Inoue, S., Alkandari, J.R., Leetongin, G., Kahlmeier, S., Lancet Physical Activity Series Working Group. 2012. The pandemic of physical inactivity: global action for public healthLancet 380, 294-305.

LeBlanc, A.G., Katzmarzyk, P.T., Barreira, T.V., Broyles, S.T., Chaput, J.P., Church, T.S., Fogelholm, M., Harrington, D.M., Hu, G., Kuriyan, R., Kurpad, A., Lambert, E.V., Maher, C., Maia, J., Matsudo, V., Olds, T., Onywera, V., Sarmiento, O.L., Standage, M., Tudor-Locke, C., Zhao, P., Tremblay, M.S., and ISCOLE research group. 2015. Are participant characteristics from ISCOLE study sites comparable to the rest of their country?Int. J. Obes. Suppl. 5, S9-S16.

McNeill, L.H., Kreuter, M.W., Subramanian, S.V., 2006. Social environment and physical activity: a review of concepts and evidence. Soc. Sci. Med. 63, 1011-1022.

Molnar, B.E., Gortmaker, S.L., Bull, F.C., Buka, S.L., 2004. Unsafe to play? Neighborhood disorder and lack of safety predict reduced physical activity among urban children and adolescents. Am. J. Health Promot. 18, 378-386.

de Onis, M., Onyango, A.W., Borghi, E., Siyam, A., Nishida, C., Siekmann, J., 2007. Development of a WHO growth reference for school-aged children and adolescents. Bull. World Health Organ 85, 660-667.

Rosenberg, D., Ding, D., Sallis, J.F., Kerr, J., Norman, G.J., Durant, N., Harris, S.K., Saelens, B.E., 2009. Neighborhood Environment Walkability Scale for Youth (NEWS-Y): reliability and relationship with physical activity. Prev. Med. 49, $213-218$

Sallis, J.F., Alcaraz, J.E., McKenzie, T.L., Hovell, M.F., 1999. Predictors of change in children's physical activity over 20 months: variations by gender and level of adiposity. Am. J. Prev. Med. 16, 222-229.

Sallis, J.F., Owen, N., Fisher, E.B., 2002a. Ecological models of health behavior. In: Glanz, K., Rimer, B.K., Lewis, F.M. (Eds.), Health Behavior and Health Education. Theory, Research, and Practice3rd ed.. Jossey-Bass, San Francisco.

Sallis, J.F., Taylor, W.C., Dowda, M., Freedson, P.S., Pate, R.R., 2002b. Correlates of vigorous physical activity for children in grades 1 through 12: comparing parent- reported and objectively measured physical activity. Pediatr. Exerc. Sci. 14, 30.

Sallis, J.F., Bowles, H.R., Bauman, A., Ainsworth, B.E., Bull, F.C., Craig, C.L., Sjostrom, M., De Bourdeaudhuij, I., Lefevre, J., Matsudo, V., Matsudo, S., Macfarlane, D.J. Gomez, L.F., Inoue, S., Murase, N., Volbekiene, V., McLean, G., Carr, H., Heggebo, L.K., Tomten, H., Bergman, P., 2009. Neighborhood environments and physical activity among adults in 11 countries. Am. J. Prev. Med. 36, 484-490.

Sampson, R.J., Raudenbush, S.W., Earls, F., 1997. Neighborhoods and violent crime: a multilevel study of collective efficacy. Science 277, 918-924.

Sarmiento, O.L., Lemoine, P., Gonzalez, S., Broyles, S.T., Denstel, K.D., Larouche, R., Onywera, V., Barreira, T.V., Chaput, J.-P., Fogelholm, M., 2015. Relationships between active school transport and adiposity indicators in school-age children from low-, middle-and high-income countries. Int. J. Obes. Suppl. 5, S107-S114.

Tremblay, M.S., Barnes, J.D., Gonzalez, S.A., Katzmarzyk, P.T., Onywera, V.O., Reilly, J.J., Tomkinson, G.R., Global Matrix 2.0 Research, T, 2016. Global matrix 2.0: report card grades on the physical activity of children and youth comparing 38 countries. J. Phys. Act. Health 13, S343-S366.

Tudor-Locke, C., Barreira, T.V., Schuna, J.M., Jr., Mire, E.F., Katzmarzyk, P.T., 2014. Fully automated waist-worn accelerometer algorithm for detecting children's sleepperiod time separate from 24-h physical activity or sedentary behaviors. Appl. Physiol. Nutr. Metab. 39, 53-57.

Tudor-Locke, C., Barreira, T.V., Schuna, J.M., Jr., Mire, E.F., Chaput, J.P., Fogelholm, M., Hu, G., Kuriyan, R., Kurpad, A., Lambert, E.V., Maher, C., Maia, J., Matsudo, V., Olds, T., Onywera, V., Sarmiento, O.L., Standage, M., Tremblay, M.S., Zhao, P., Church, T.S., Katzmarzyk, P.T.,, ISCOLE research group. 2015. Improving wear time compliance with a 24-hour waist-worn accelerometer protocol in the International Study of Childhood Obesity, Lifestyle and the Environment (ISCOLE)Int. J. Behav. Nutr. Phys. Act. 12, 11.

United Nations Development Programme. Human Development Report, 2011[Online]. Available: 〈http://www.undp.org/content/dam/undp/library/corporate/HDR/ 2011\%20Global\%20HDR/English/HDR_2011_EN_Complete.pdf) (Accessed 4 August 2014)

World Bank, 2012. World Development Indicators 2012. World Bank, Washington, DC.

World Health Organization, 2010. Global Recommendations on Physical Activity for Health. World Health Organization, Geneva, Switzerland. 